\title{
Study and comparison of the rate of energy dissipation in stepped overflows before and after hydraulic jump using laboratory model
}

\author{
Moussa Rassaei ${ }^{1}$, Sedigheh Rahbar ${ }^{2}$ \\ ${ }^{1}$ Islamic Azad University Dehdasht branch, Iran \\ ${ }^{2}$ Islamic Azad University yasuj branch, Iran
}

\begin{abstract}
The Stepped spillway consists of steps that starts of near spillway crest and continues downstream heels The use of a stepped spillway, has been common since ancient times. But because of the significant impact of steps, on the energy dissipation flow, in recent years, due to this type of Spillways has been greater Also, understanding new technologies, use of Materials, Roller compact Concrete and consistent The manufacturing method with spillway mentioned make use of stepped Spillways has a large number of projects.In this paper, the use of physical models built in the Hydraulic Laboratory, Azad University of Dehdasht, flow was passed on stepped spillway and by measuring depth of water, before and after hydraulic jump, were calculated the rates of energy dissipation. The results of this research show that, due to the entry of air into water flow passing through, on stepped overflows, use a water depth before the hydraulic jump in downstream order to determine the energy loss, is caused estimating more (unrealistic) energy loss relative. In fact, with entry of air bubbles into the flow (reduction of viscosity), reduced of the rate shear stress, and consequently the relative energy dissipation properties, will be reduced. Also entry of air bubbles into the flow, causing increased volume of flow and measurement, depth flow, which makes with error.
\end{abstract}

Keywords: stepped spillway, energy dissipation, hydraulic jump

\section{INTRODUCTION}

Stepped spillway, including structures that, order to energy dissipation and reducing of water erosion is used over a period of river, which has a slope is steep,. Stepped spillway, is a hydraulic structures, very powerful of Climactic spillway in Amortize the flow energy and reduce erosion downstream of the dams. When the water flow by spillway from the reservoir to water surface in downstream, to falls, the potential energy is converted to kinetic energy. This energy, in the form high-speed in downstream is appears, that, for the prevention of river erosion in downstream, is necessary to install facilities such as Stepped spillways, is amortized. During the investigation, it was observed that, the flow passing over a stepped spillway, and also deal with successive steps, built on the steep side, as a foamy water (White water), in toe spillway occurs. Entry, high bubbles of air into the flow (foamy pollution of water), reduces shear stress and reduces of energy dissipation properties. Because most of the energy dissipation, on effect of shear stress between water molecules and the by entry of air bubbles into the flow, is reduced of energy dissipation properties.on the other hand, the entry of high bubbles of air into the flow leads to depth water increase in the toe of the spillway, and in Calculating of energy dissipation between different researchers, discrepancies that arise. The last comments for calculating depth of water in the downstream spillway should be used deep of Pure water (water without air bubbles). Papers and various reports, show that the use of foamy water depth, by some researchers, is led to high estimates of energy dissipation (the unreal).In this research, a physical model, was considered accordance with table 1, with 10 steps and with 3 discharge, $0.01852,0.02622$ and $0.03131\left(\mathrm{~m}^{3} / \mathrm{s}\right)$ and slope of 45 degrees, and, flowing water of over it was passed and whit observation type of passing flow over the spillways, depth water before and after the hydraulic jump by graded index, equipped on vernyeh with precision of $0.1(\mathrm{~mm})$, in Three points were measured, and the average of three measurements was used on the cross section, in calculation of energy dissipation. Considering whit contents of the above, for showing, the obtained error of measurement, depth flow (the depth of the initial flow before the jump), in determining the energy dissipation, the rate of energy dissipation relative to the use of two methods using of direct measurement of the depth before of hydraulic jump and using of the sequent depth after the hydraulic jump and calculated depth $\left(\mathrm{y}_{1}\right)$, via relationship of hydraulic jump, is performed. 


\section{THEORETICAL RESEARCH}

\subsection{TYPES OF FLOW IN STEPPED SPILLWAYS}

1.1.1 NAPPE Flow REgime: The flow, that which free jet, Collision of the upper step, to lower step. This type of flow, occurs in low Discharge and high-tall steps. (Fig 1.)

1.1.2 Skimming Flow Regime: In the Skimming Flow Regime, steps act such as big coarseness against the flow. (Fig 2.)

1.1.3 Transitional FLOW REgime: If the crossing flow over the stepped spillways with slop and Arbitrary number of steps , at low Discharge a stat is falling, Gradually, then Discharge is increased, a case is observed, at the boundary between two Flow the Skimming and Nappe and the conversion threshold is, to Skimming Flow Regime, that this type of flow, is called transitional flow regime

\subsection{THE GOVERNING EQUATIONS IN THE ENERGY DISSIPATION}

\subsubsection{ENERGY DISSIPATION, IN EFFECT, THE PHENOMENON OF HYDRAULIC JUMP}

Supercritical flow in downstream (toe) spillway or the vertical slope breaker, after the formation of hydraulic jump will become to sub-critical flow, and much of its energy, is depreciated the effect on formation of hydraulic jump. The importance of energy dissipation, the effect of hydraulic jump, relating to, stepped spillway whit very gentle slope and whit the occurrence nappe flow regime is over spillway.

By using of the equations of energy and momentum and continuity, equations determine the energy dissipation resulting from hydraulic jump is easily provable.

$$
\begin{array}{ll}
\mathrm{h}_{\mathrm{lj}}=\mathrm{E}_{\mathrm{S} 1}-\mathrm{E}_{\mathrm{S} 2}=\mathrm{y}_{1}+\frac{\mathrm{v}_{1}^{2}}{2 \mathrm{~g}}-\left(\mathrm{y}_{2}+\frac{\mathrm{v}_{2}^{2}}{2 \mathrm{~g}}\right) & \text { equations of energy } \\
\mathrm{h}_{\mathrm{lj}}=\mathrm{y}_{1}+\mathrm{h}_{\mathrm{v} 1}-\left(\mathrm{y}_{2}-\mathrm{h}_{\mathrm{v} 2}\right)=\frac{\left(\mathrm{y}_{2}-\mathrm{y}_{1}\right)^{3}}{4 \mathrm{y}_{1} \mathrm{y}_{2}} & \text { equations of energy }
\end{array}
$$

$\frac{1}{2} \gamma \mathrm{y}_{1}^{2}-\frac{1}{2} \gamma \mathrm{y}_{2}^{2}=\rho \mathrm{q}\left(\mathrm{v}_{2}-\mathrm{v}_{1}\right)$

Momentum equation for rectangular cross section

$q=y_{1} v_{1}=y_{2} v_{2}$

$\mathrm{h}_{\mathrm{lj}}=\frac{\left(\mathrm{y}_{2}-\mathrm{y}_{1}\right)^{3}}{4 \mathrm{y}_{1} \mathrm{y}_{2}}$

Continuity equation for discharge per unit width

Equation of energy dissipation in a hydraulic jump

$\frac{y_{2}}{y_{1}}=\frac{1}{2}\left(\sqrt{1+8 \mathrm{~F}_{\mathrm{r} 1}^{2}}-1\right)$

Public relations Hydraulic Jump

In the above equation, $Y_{1}$ and $Y_{2}$ conjugate depths before and after the hydraulic jump, $V_{1}$ and, $V_{2}$ mean flow velocity before and after the hydraulic jump, $\mathrm{h}_{\mathrm{lj}}$ energy dissipation into hydraulic jump and $\mathrm{Fr}_{1}$ Froude number in place before Jump hydraulic.

\subsubsection{ENERGY DISSIPATION SPILLOVERS AND VERTICAL SLOPES BREAKER}

In all the subjects that are offered in different seasons of this research, the order of energy dissipation, include of difference between energy in upstream of the spillway or the vertical slope breaker and energy in downstream (toe), in location form depth, before hydraulic jump, (initial depth), which to following is shown.

$$
\Delta H=H_{t}-H_{1}=\left(1.5 Y_{C}+H_{d a m}\right)-\left[y_{1}+\frac{v_{1}^{2}}{2 g}\right]
$$

Also The relative energy dissipation, is defined as follow:

$\frac{\Delta \mathrm{H}}{\mathrm{H}_{\mathrm{t}}}=\frac{H_{\mathrm{t}}-\mathrm{H}_{1}}{\mathrm{H}_{\mathrm{t}}}=1-\frac{H_{1}}{\mathrm{H}_{\mathrm{t}}}=1-\frac{\left[y_{1}+\frac{v_{1}^{2}}{2 g}\right]}{1.5 Y_{C}+H_{d a m}}$

In the above relation, are $\mathrm{H}_{\mathrm{t}}$, total energy in the upstream spillway, $\mathrm{H}_{\mathrm{l}}$, energy in toe and before the hydraulic jump, $\mathrm{H}_{\text {DAM }}$, total height spillway, h, height of step, yc and $\mathrm{Y}_{1}$, respectively, the critical depth and the depth before hydraulic jump and $\mathrm{V}_{1}$, average speed before the hydraulic jump.

\section{DESCRIPTION OF THE ISSUE}

\subsection{GEOMETRICAL CHARACTERISTICS AND HYDRAULICAL SPILLWAY}

In this research, was used the characteristics of physical models (according to table 1), Hydraulic Laboratory, Azad University of Dehdasht. In this research, was considered a physical model of, stepped spillway, and experiments with Discharge of $0.01852,0.02622$ and $0.03131\left(\mathrm{~m}^{3} / \mathrm{s}\right)$ was performed onto tmodel. That, in this model, Has with 10 steps and a slope of 45 degrees, so that the height spillways of $8.5(\mathrm{~cm})$. height of Spillway model, was considered the constant and equal to $1 \mathrm{~m}$. the Section curved shape of the spillway (crest), was designed with the equation $\mathrm{y}=1.68 \mathrm{X}^{1.85}$. Flow was passed onto, Spillway model, and with measuring, depth of water, before the hydraulic jump, $\left(\mathrm{Y}_{1}\right)$ and the sequent depth of hydraulic jump, $\left(\mathrm{Y}_{2}\right)$, were calculated the rate of energy dissipation, per two cases and the results, together, were compared. 
Study and comparison of the rate of energy dissipation in stepped overflows before and after

Table 1 - Characteristics of the physical model spillway built.

\begin{tabular}{|c|c|c|c|c|c|c|}
\hline Gender Spillway & $\begin{array}{l}\text { Height } \\
\text { of } \\
\text { model } \\
(\mathrm{cm}) \\
\end{array}$ & $\begin{array}{l}\text { Horizontal } \\
\text { length } \\
\text { of Spillway } \\
\\
\text { (cm) }\end{array}$ & $\begin{array}{l}\text { Height } \\
\text { Of } \\
\text { Spillway } \\
\\
(\mathrm{cm})\end{array}$ & $\begin{array}{l}\text { Width } \\
\text { Of } \\
\text { Flume } \\
(\mathrm{cm}) \\
\end{array}$ & $\begin{array}{l}\text { Number } \\
\text { of } \\
\text { Spillway }\end{array}$ & $\begin{array}{c}\text { The slope } \\
\text { of } \\
\text { Spillway }\end{array}$ \\
\hline Galvanized iron & 100 & 8.5 & 8.5 & 50 & 10 & 45 \\
\hline
\end{tabular}

\subsection{Calculation Of Energy dissipation}

Experiments was performed for three types of Discharge $0.01852,0.02622$ and $0.03131\left(\mathrm{~m}^{3} / \mathrm{s}\right)$, onto model was built and by measuring depths before and after the hydraulic jump, were calculated the rates of energy dissipation and in Table (2) were recorded. results of investigations the phenomenon air entry into the flow and the resulting erro of measurement, depth of flow, in calculated energy dissipation, is shown in Figure 2. in Figure 2, is used in vertical axis, the dimensionless parameter, the relative energy dissipation. That form, $\frac{\Delta \mathrm{H}}{\mathrm{H}_{\mathrm{t}}}=\frac{\mathrm{H}_{\mathrm{t}}-\mathrm{H}_{1}}{\mathrm{H}_{\mathrm{t}}}=1-\frac{\mathrm{H}_{\mathrm{t}}}{\mathrm{H}_{1}}$, is defined, which, at that is, $\mathrm{Ht}$, total upstream energy of the spillway $(\mathrm{m})$, and $\mathrm{H}_{1}$, downstream energy of the spillway (toe), and before the hydraulic jump (m). also it is necessary that amount, $\mathrm{H} 1$, to be calculated the following two ways.

- Use of the measured depth of flow before the hydraulic jump, $\left(\mathrm{Y}_{1}\right)$, which, at this Section, Air entry and fluctuating significantly water, the accuracy of measurement decreases.

- Use of the measured depth of flow after the hydraulic jump $\left(\mathrm{Y}_{2}\right)$, and then calculated depth $\left(\mathrm{Y}_{1}\right)$, with application famous relationship, depths conjugate of hydraulic jump.

\section{CONCLUSIONS}

According to Table (2) and Figure (2) can be noted the following results:

- In calculating the relative energy dissipation, $\left(\frac{\Delta \mathrm{H}}{\mathrm{H}_{\mathrm{t}}}\right)$, direct application depth before the hydraulic jump $\left(\mathrm{Y}_{1}\right)$, estimated the rate of energy dissipation more, compared to depth of after the hydraulic jump $\left(\mathrm{Y}_{2}\right)$. The reason is that, with the use of depth $Y_{1}$, is which contains a mixture of air and water, depth of flow measurement, more than reality, and consequently estimated is energy at the toe of spillway, lower than a fact. But with use of depth, $\mathrm{Y}_{2}$, and then calculated depth $\mathrm{Y}_{1}$, by famous relationship the depths of hydraulic jump, the depth of pure water (Without air of bubbles), in toe of spillway, is entered in the calculations, and ultimately, the difference in calculation of energy dissipation from here, is the result. Therefore, use of the depth of pure water and Without air, for calculate the energy dissipation, is more logical because a large part of the energy dissipation, on effect of shear stress between the water molecules occurs, and no shear stress between molecules of air (density of water is 800-fold the density of air).

by increasing the flow discharge, is increased, the difference between flow energy dissipation by using depth before and after the hydraulic jump. This is consistent with observations. Because, with increased flow discharge, on amount of water pollution foaming, (entrance, high air bubbles into the flow), added, and measuring depth of flow before the hydraulic jump, more than the actual value, determined and, therefore estimate the energy dissipation by using the measured depth is with more error, before the hydraulic jump.

\section{RESOURCES AND REFERENCES}

[1] Boes, R.M. Hager, H.W. 2003, Hydraulic design of stepped spillways, Journal of Hydraulic Engineering. ASCE, Vol.129, No.9, 671- 679

[2] Chamani, M.R. and Rajaratnam, N, Jet flow on stepped spillways, Journal of Hydraulic ASCE, Engineering. Vol.120, No.2, 254-259

[3] Chamani, M.R. Rajaratnam, N, Onset of skimming flow on stepped spillways, Journal of Hydraulic Engineering. ASCE, Vol.125, No.9, 969-971

[4] Chen, Q. Dai, G. Liu, H, Volume of fluid model for turbulence numerical simulation of stepped spillway overflow, Journal of Hydraulic Engineering, ASCE, Vol.128, No.7, 683-688.

[5] Christodoulou, G.C, Energy dissipation on stepped spillway, Journal of Hydraulic Engineering, ASCE, Vol.119, No.5, 644-649.

[6] Salmasi. f, Hydraulic Evaluation of stepped spillways by using physical models, doctoral diss, University of shahi Chamran, ahvaz, iran, 2003. 
Study and comparison of the rate of energy dissipation in stepped overflows before and after

Table 2 - Measurement and Calculation of hydraulic parameters for overflows stepped with specification

\begin{tabular}{|c|c|c|c|}
\hline $\begin{array}{c}\text { Hydraulic } \\
\text { characteristics }\end{array}$ & Test 1 & Test 2 & Test 3 \\
\hline $\mathrm{Q}(\mathrm{m} 3 / \mathrm{s})$ & 0.01852 & 0.02622 & 0.03131 \\
\hline$q(\mathrm{~m} 2 / \mathrm{s})$ & 0.038 & 0.054 & 0.064 \\
\hline$Y_{1}(\mathrm{~m})$ & 0.029 & 0.039 & 0.036 \\
\hline $\mathrm{V}_{1}(\mathrm{~m} / \mathrm{s})$ & 1.30 & 1.37 & 1.77 \\
\hline Fn & 2.44 & 2.22 & 2.99 \\
\hline Ht (m) & 1.09 & 1.11 & 1.12 \\
\hline $\mathrm{H}_{1}(\mathrm{~m})$ & 0.116 & 0.135 & 0.197 \\
\hline$\Delta \mathbf{H}=\mathbf{H t}-\mathbf{H}_{1}$ & 0.973 & 0.975 & 0.925 \\
\hline$\Delta \mathrm{H} / \mathrm{Ht} \%$ & 89.39 & 89.84 & 82.48 \\
\hline $\mathbf{Y}_{\mathrm{C}}(\mathbf{m})$ & 0.053 & 0.066 & 0.075 \\
\hline $\mathbf{Y}_{\mathrm{C}} / \mathrm{h}$ & 0.619 & 0.780 & 0.878 \\
\hline $\mathrm{Y}_{2}(\mathrm{~m})$ & 0.104 & 0.131 & 0.172 \\
\hline $\mathrm{Y}_{1}(\mathrm{~m})$ & 0.022 & 0.028 & 0.025 \\
\hline$V_{1}(\mathrm{~m} / \mathrm{s})$ & 1.70 & 1.91 & 2.60 \\
\hline Fn & 3.65 & 3.64 & 5.28 \\
\hline Rn*1000 & 37.80 & 53.51 & 63.90 \\
\hline $\mathrm{H}_{1}(\mathrm{~m})$ & 0.17 & 0.214 & 0.368 \\
\hline$\Delta \mathbf{H}=\mathbf{H t}-\mathbf{H}_{1}$ & 0.919 & 0.896 & 0.754 \\
\hline$\Delta \mathrm{H} / \mathrm{Ht} \quad \%$ & 84.38 & 80.72 & 67.19 \\
\hline ERROR & 5.94 & 11.3 & 22.76 \\
\hline
\end{tabular}

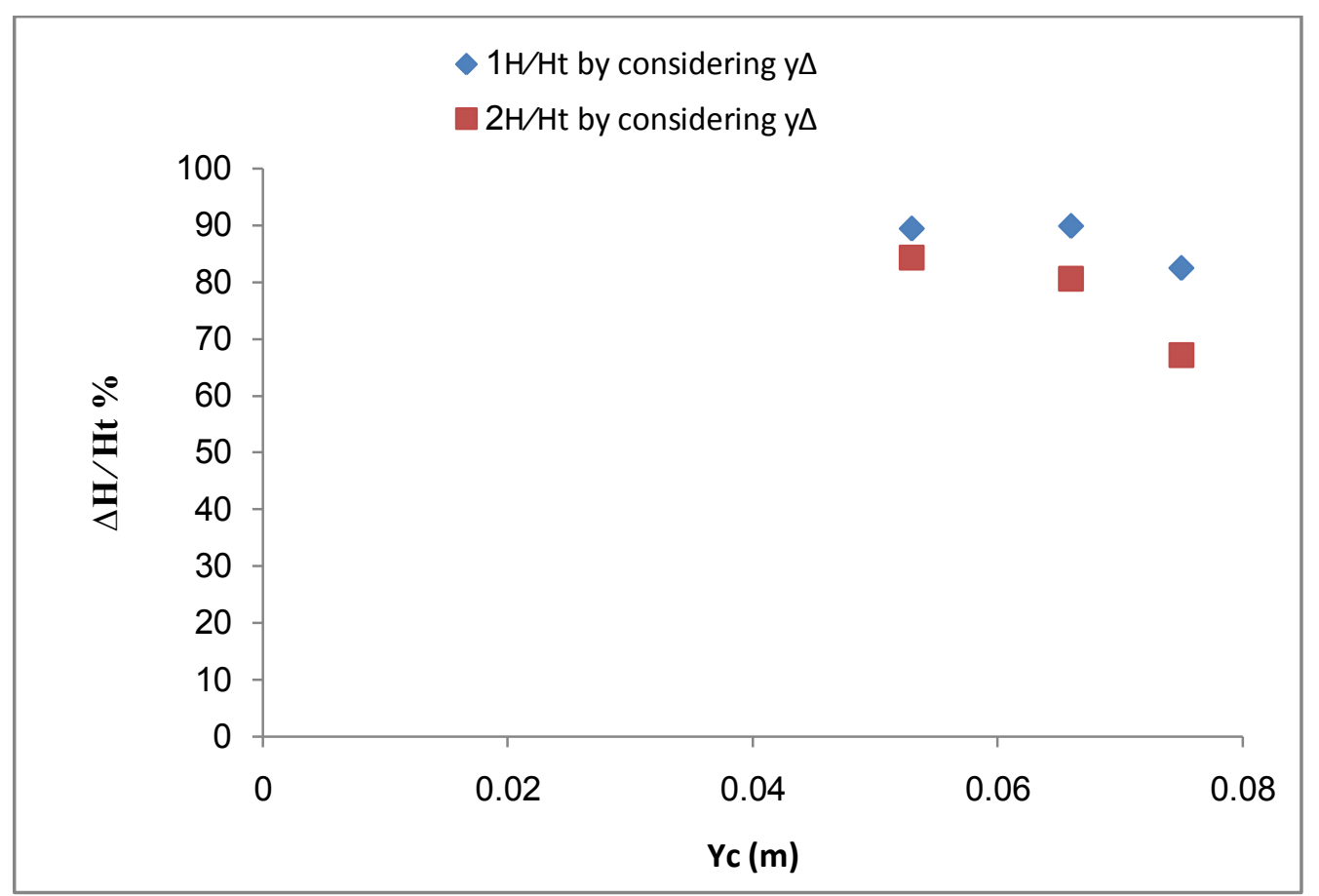

Figure 2 - Comparison of the rate energy dissipation, flow by taking depth y1 and y2 